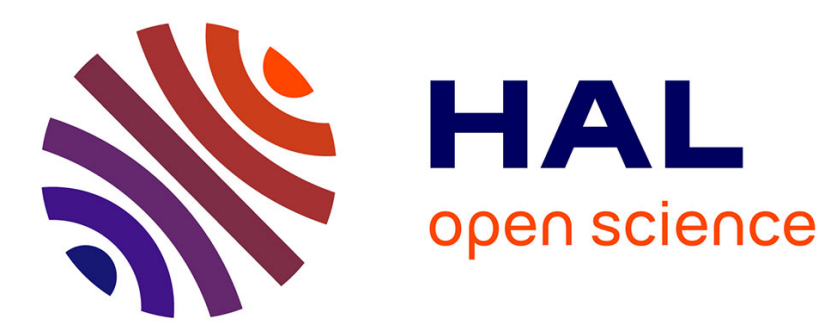

\title{
Solids fracturing by crystallization pressure through metastability-driven pathways
}

Lionel Mercury, Claudie Hulin, Arnault Lassin

\section{To cite this version:}

Lionel Mercury, Claudie Hulin, Arnault Lassin. Solids fracturing by crystallization pressure through metastability-driven pathways. Colloids and Surfaces A: Physicochemical and Engineering Aspects, 2021, pp.127277. 10.1016/j.colsurfa.2021.127277 . insu-03313453

\section{HAL Id: insu-03313453 \\ https://hal-insu.archives-ouvertes.fr/insu-03313453}

Submitted on 4 Aug 2021

HAL is a multi-disciplinary open access archive for the deposit and dissemination of scientific research documents, whether they are published or not. The documents may come from teaching and research institutions in France or abroad, or from public or private research centers.
L'archive ouverte pluridisciplinaire HAL, est destinée au dépôt et à la diffusion de documents scientifiques de niveau recherche, publiés ou non, émanant des établissements d'enseignement et de recherche français ou étrangers, des laboratoires publics ou privés. 


\section{Journal Pre-proof}

Solids fracturing by crystallization pressure through metastability-driven pathways

Lionel Mercury, Claudie Hulin, Arnault Lassin

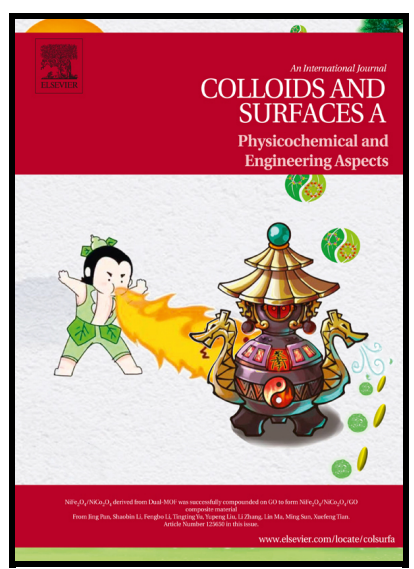

PII: $\quad$ S0927-7757(21)01146-8

DOI: $\quad$ https://doi.org/10.1016/j.colsurfa.2021.127277

Reference: COLSUA127277

To appear in: Colloids and Surfaces A: Physicochemical and Engineering Aspects

Received 26 May 2021

date:

Revised date: 23 July 2021

Accepted 27 July 2021

date:

Please cite this article as: Lionel Mercury, Claudie Hulin and Arnault Lassin, Solids fracturing by crystallization pressure through metastability-driven pathways, Colloids and Surfaces A: Physicochemical and Engineering Aspects, (2021) doi:https://doi.org/10.1016/j.colsurfa.2021.127277

This is a PDF file of an article that has undergone enhancements after acceptance, such as the addition of a cover page and metadata, and formatting for readability, but it is not yet the definitive version of record. This version will undergo additional copyediting, typesetting and review before it is published in its final form, but we are providing this version to give early visibility of the article. Please note that, during the production process, errors may be discovered which could affect the content, and all legal disclaimers that apply to the journal pertain.

(C) 2021 Published by Elsevier. 
Solids fracturing by crystallization pressure through metastability-driven pathways

Lionel MERCURY ${ }^{1, \star}$, Claudie HULIN ${ }^{1}$, and Arnault LASSIN ${ }^{2}$

${ }^{1}$ Institut des Sciences de la Terre d'Orléans, UMR 7327 Université d'Orléans, CNRS, BRGM, 1 A rue de la Férollerie, 45071 Orléans cedex (France).

${ }^{2}$ BRGM, DEPA/MG2, 3 Avenue Claude Guillemin, 45060 Orléans

Corresponding author: lionel.mercury@univ-orleans.fr. Institut des Sciences de la Terre d'Orléans, UMR 7327 U. d'Orléans / CNRS-INSU / BRGM. 1A rue de la Férollerie, 45071 Orléans Cedex. France. Tel.: +33 (0)238.404.075. Fax: $+33(0) 238.494 .476$

Keywords: Crystallization pressure; Supersaturation; Phase transitions, Interfacial processes.

\section{Abstract}

The salt damage provoked by crystallization pressure due to salt growth inside a porous material requires a certain supersaturation of the pore solution. The itineraries to build it are here revisited at the one pore scale, through experiments allowing direct observations of the multistep processes as well as the visualization of the damage itself.

We present phase transitions experiments within silica micro-capillaries filled with Na-SO4 aqueous solution submitted to: (i) drying by isothermal evaporation, (ii) temperature change, and (iii) the cavitation of a metastable capillary-type liquid.

We directly observed the multistep processes that drive salt damage due to in-pore crystal growth, until the container is fractured, for the first time to our knowledge. We thus demonstrate that supersaturation (linked to direct drying, temperature drop, or capillarity) allows the salt damage to happen as a brutal process. Interestingly, the newly-observed capillary mechanism, never described in the literature to our knowledge, can take place after a long latency period without any apparent immediate triggering cause.

Those findings magnify the versatility of the crystallization pressure that can occur in very contrasted situations. They also enforce the fact that this chemo-mechanical coupling is strongly pore-size dependent, with the third process that should 
predominate in cement and stones hosting nanoscale porosity prone to strong capillarity.

\section{INTRODUCTION}

The crystallization of salts is a primary cause of mechanical damage for natural rocks and building materials in a large range of environments [1,2]. Salt weathering is a commonplace phenomenon in Nature, particularly intense in arid hot deserts as Jordan and Egypt [3], cold deserts as the Antarctic continent [4-6], and coastal areas [1-2]. In those regions, the supply of salt and repeated wetting-drying cycles are conducive to in-pore salt precipitation that may trigger poromechanical constraints. The same is known for building stones used for long by mankind so that a quantitative understanding of the salt damage, how it proceeds, how remediating it, or preventing it, has got strong implications for the preservation of our cultural heritage. Beyond this usual context to which the crystallization pressure is usually linked, it may be of paramount importance in man-made processes to exploit the underground. Extraction and storage of energy $\left(\mathrm{H}_{2}\right.$ or biogas, for instance) or management of various wastes $\left(\mathrm{CO}_{2}\right.$ and nuclear wastes, typically) generate drying over huge volume of normally saturated hydrosystems, and introduce permanent or long-term drying mechanisms with many issues at stake (injectivity, wells near-field, tight gas reservoirs exploitability, safety of nuclear waste repositories, etc.).

In confined pore spaces, growing salts can exert a pressure against the solid wall possibly leading to its rupture (e. g., [2,6-12]). A salt fills in a pore and keeps on growing upon the pore surface, on which it exerts a compressive stress. To continue to grow upon the loaded surface, a film of solution must persist between the crystal and the pore wall [7, 13-14] and remain stable against the pressure exerted by the salt. The liquid film originates from repulsive forces between solid faces, expressed by the disjoining pressure, and so it is expected to be a few nanometers thin [15]. The second important notion is that the growth does not stop despite the growing pressure (which typically increases solubility ....) because it is driven by the supersaturation in the solution that makes the growth spontaneous as long as any chemical excess remains. Indeed, these two important features (persistence of the liquid film and supersaturation of the pore solution) maintain the continuous supply of ions that are necessary for the crystal growth. One of the main questions is: how to generate such supersaturation in the solution with respect to salt, especially in heterogeneous porous media with many potential nucleation sites [16-17] which lower the barrier towards crystallization?

Sodium sulfate salts are recognized to be particularly damaging, notably because two polymorphs of contrasted solubility and molar volumes offer the required supersaturation threshold to build up significant crystallization pressure. They are so destructive that they have been used as an analogue of frost to test the durability of stones since the beginning of the $19^{\text {th }}$ century (e.g., [18]). Porous materials are affected by sodium sulfate during wetting drying cycles or rising damp experiments $[7,9-10,12]$. Basically, salt damage is promoted whenever rocks undergo cyclic variations of temperature [19] or humidity [20], especially if the porous network is heterogeneous, well connected and contains micropores [1,10,21]. 
Despite these advances, the processes leading to such degradations are not fully understood in detail $[7,12,16,22]$. In particular, the controlling mechanisms causing the supersaturation driving force are not so well known. More exactly, diverse sources may be linked to drying removal of water (growing concentration), or temperature change (change of the equilibrium constant and thus of the solubility). However, even without significant drying rate, salt damage can occur at constant temperature (e.g., [17] and references therein), posing the problem of the mechanism(s) to build supersaturation. One proposition is to assume that the 'active' large pore, wherein one crystal grows, is connected to one (or more) very small pore, the reduced porosity of which results in a significant change of the solubility. The sketch requires the liquid film located in between the growing solid and the pore wall be diffusively equilibrated with the small pore body reservoir. As a consequence, the liquid film becomes supersaturated with respect to the thermochemical equilibrium that applies in a large pore. It also requires that the lifetime of the situation is longer than the diffusion time equilibration, for the supersaturation to reach the fracture threshold. The fracturing extent would be expected only within the zones having large-to-narrow pores direct links.

The first aim of this paper is to produce new observation data on the different sketches that account for creating supersaturation in heterogeneous pores using the classic drying and thermal change processes. In addition, a novel process is explored with the role of the superheating metastability, which can be expected in unsaturated porous media whenever large-to-thin pores connectivity arises (ink bottle shape; e.g., [23]). Basically, this effect originates the well-known hysteresis processes in soil water retention curves.

Analogous experiments inside transparent silica micro-capillaries are here carried out, enabling to observe any phase transitions and/or fracturing optically in well controlled conditions. Initially, each micro-capillary is a monosized very large channel $(>200 \mu \mathrm{m})$, infilled with known composition salt solution of sodium sulfate, then submitted to certain temperature-relative humidity $(T-R H)$ conditions. The initial very large monosized channel evolves through time with salt precipitation, leading to a dual pore system with a very large pore size contrast.

Throughout this study, we recorded direct visualization of commonly-admitted sequences of events that result into final fracturing. Beyond this, observations of how $\mathrm{T}-\mathrm{RH}$ conditions and topology of porous network (evolving through time) trigger salt damage, allowed us to imply different types of metastability cooperating in such process due to multiphase/multiscale porosity.

\section{MATERIALS AND METHODS}

\subsection{Materials}

Salt crystallization and associated effects have been observed in microcapillary tubes. We used rectangular (width $1000 \mu \mathrm{m} x$ depth $100 \mu \mathrm{m})$ and cylindrical $(200 \mu \mathrm{m}$ internal diameter) capillaries, made of borosilicate glass from VitroCom (Vitro TubesTM). 
$\mathrm{Na}_{2} \mathrm{SO}_{4}$ solutions were prepared by dissolving thenardite crystals (NormaPur powder) in distilled water at $45^{\circ} \mathrm{C}$ and stored at this constant temperature and $90 \%$ relative humidity $(\mathrm{RH})$ of air in a climate chamber (HPP 108, Memmert technology). Two mother solutions were prepared: $33.3 \mathrm{wt} \%$ or $3.52 \mathrm{~mol}^{\mathrm{kg}} \mathrm{k}^{-1}$ and $15 \mathrm{wt} \%$ or 1.24 mol.kg-1.

The identification of crystals (mirabilite vs. thenardite) growing in the micro-capillaries is mainly based on the observation of the crystal morphology (Fig. 1A): cones or 'massive' strips for hydrous mirabilite while anhydrous $\mathrm{Na}_{2} \mathrm{SO}_{4}$ appears first as micrograins or dendrites and then evolves toward massive macrocrystals. The relationship between salt and morphology is well known in the literature (e.g., [7,22]), and have been confirmed using XRD analysis on sodium sulfate salts equilibrated within the temperature range of stability of each crystal. Observations were performed with a Leica DM2500 M light microscope in a thermostated room $\left(20^{\circ} \mathrm{C}\right)$, equipped with objectives of $5 \mathrm{X}, 10 \mathrm{X}, 20 \mathrm{X}$ and $50 \mathrm{X}$ magnification, and a Leica DFC295 digital camera (image resolution: 3 megapixels, $2048 \times 1536$ ). To avoid any heat transfer, we reduced exposure to microscope lights to the minimum possible.

Given the high salinities considered in the study, the solubilities and thermodynamic properties of solution are calculated based on the Pitzer model. We decided to adopt the Cold Chem parameterization [24], to be able to extrapolate the calculations well below $0^{\circ} \mathrm{C}$ (Figure 1; See also the annex). At $20^{\circ} \mathrm{C}$ (laboratory temperature), the calculated saturation with respect to thenardite is $34.2 \mathrm{wt} \%$ or $3.66 \mathrm{~mol}^{\mathrm{kg}} \mathrm{kg}^{-1}$, while the saturation with respect to mirabilite is reached at $16.1 \mathrm{wt} \%$ or $1.35 \mathrm{~mol} . \mathrm{kg}^{-1}$, in close agreement with the available data and calculations (see the very complete paper from [25], and the references therein). Despite its lower stability with respect to mirabilite, the metastable heptahydrate $\left(\mathrm{Na}_{2} \mathrm{SO}_{4}: 7 \mathrm{H}_{2} \mathrm{O}\right)$ must also be considered since it has been observed very often during cooling experiments (e.g., [27-28]). At $20^{\circ} \mathrm{C}$, the saturation of the brine with respect to the heptahydrate is $31.2 \mathrm{wt} \%$ or 3.19 mol.kg-1. For temperature below $32^{\circ} \mathrm{C}$, any solution reaching equilibrium with thenardite is obviously highly supersaturated with respect to mirabilite (Fig. 1B). For instance, the supersaturation ratio is defined as $\log \left[\mathrm{K}_{\text {Thenardite. }} . \mathrm{aw}^{10} / \mathrm{K}_{\text {Mirabilite }}\right]$ where $\mathrm{K}$ is the equilibrium constant and aw the water activity. At $20^{\circ} \mathrm{C}$, it reaches 3.47 what can induce a crystallization pressure of $13.8 \mathrm{MPa}$, using the equation 7 from [25]. 
A.
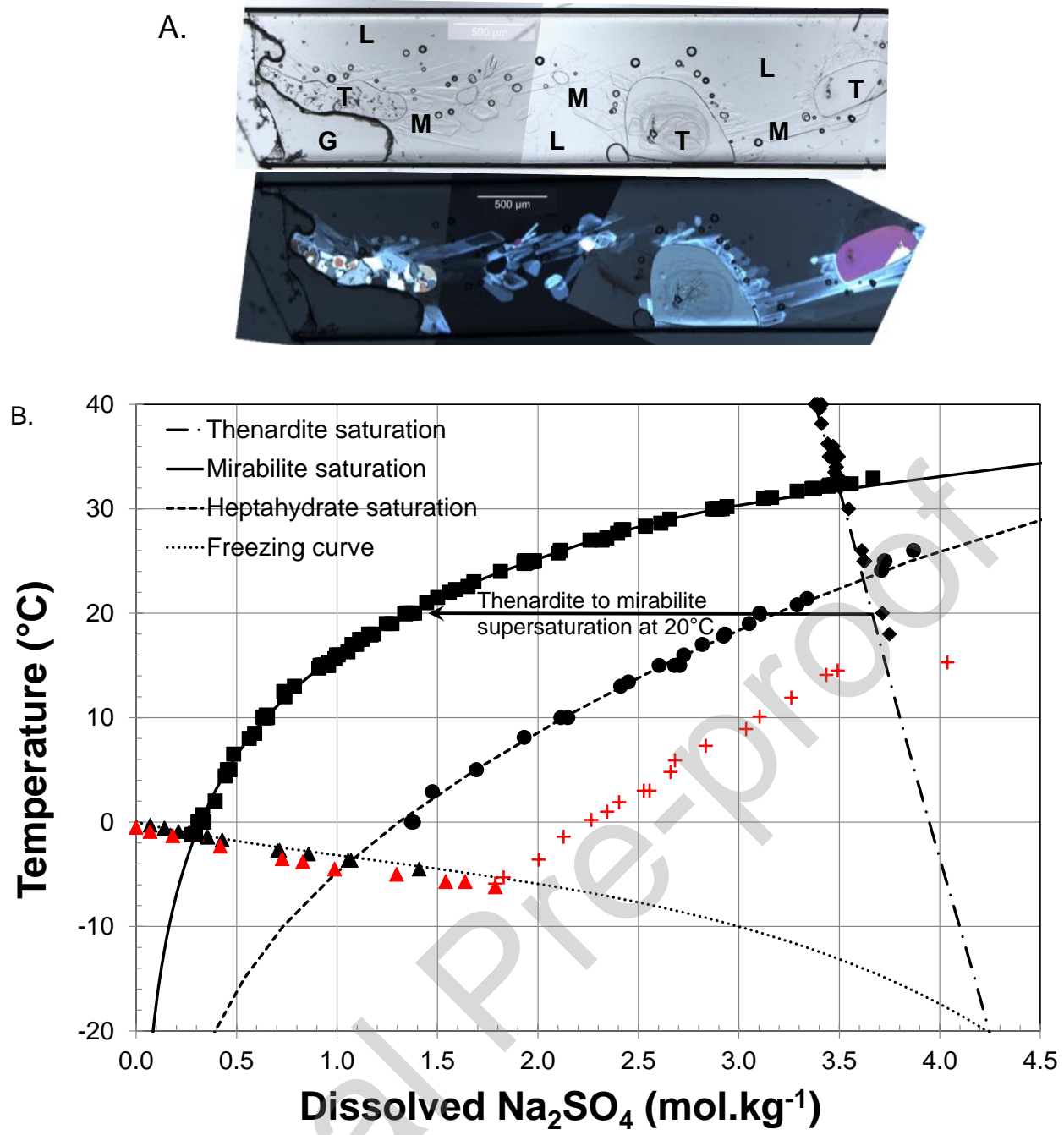

Figure 1. A, Mirabilite and thenardite crystalline habit, allowing an optical recognition (upper = natural light, lower = analysed polarized light) of each phase. L: liquid region, G: air, $\mathrm{T}$ : thenardite, $\mathrm{M}$ : mirabilite. $\mathrm{B}$, phase diagram of sodium sulfate (see text). The curves are calculated according to [24] (see text), and the full black symbols are experimental saturation data gathered in [25] (courtesy of M. Steiger); diamonds: thenardite, squares: mirabilite, circles: heptahydrate, triangles: freezing curve. Red triangles are freezing data reported as ice supercooling ([25], courtesy of M. Steiger). Red crosses are data about heptahydrate supersolubility ([25], courtesy of M. Steiger).

\subsubsection{Experimental procedure}

Capillaries were partially (approximately 4/5) infilled with salt solution and left to evaporate in the climate chamber at a controlled relative humidity $\left(48 \% \mathrm{RH}, 20^{\circ} \mathrm{C}\right)$, that is to say a moderate drying rate that promotes high supersaturation ratio in small volume [26].

A mass of thenardite was driven to precipitation through a first drying cycle on the low concentration solution (16.1\% wt). Evaporation lasted around one month before $\mathrm{Na}_{2} \mathrm{SO}_{4}$ first precipitates as the metastable dendritic polymorph III, rapidly replaced minutes later by small grain crystals of polymorph $\mathrm{V}$ (thenardite) as already observed 
before (e.g., $[7,29])$. Polymorph III of $\mathrm{Na}_{2} \mathrm{SO}_{4}$ never re-appeared in our experiments, and so the $\mathrm{Na}_{2} \mathrm{SO}_{4}$ solid phase is restricted to the polymorph $\mathrm{V}$ thenardite in what follows. The molality ratio with respect to thenardite saturation at the time of precipitation was 1.14 to 1.27 , calculated from the time evolution of the solution-air menisci receding (i.e., volume of the solution) in the microcapillary with evaporation. The solution was kept evaporating eventually leading to either a massive unique thenardite crystal (Fig 2, upper left), or a complex texture associating massive crystals and crystal grains (Fig. 2, upper right).

The subsequent stage starts when the only remaining solution is trapped in-between the massive crystals and the silica tube walls (Fig. 2, upper left and lower panels). Interestingly, the thickness of this liquid layer can be roughly estimated by the optical irisations visible under optical microscope, meaning a thickness commensurable to the wavelength of light (let's say, $600 \mathrm{~nm}+/-50 \%$ ). This liquid layer evaporates with a very slow rate, since experiments lasted over months without visible loss of water. As a consequence, it can be expected the whole solution trapped in between thenardite and capillary wall to reach local chemical equilibrium with the thenardite crystal.

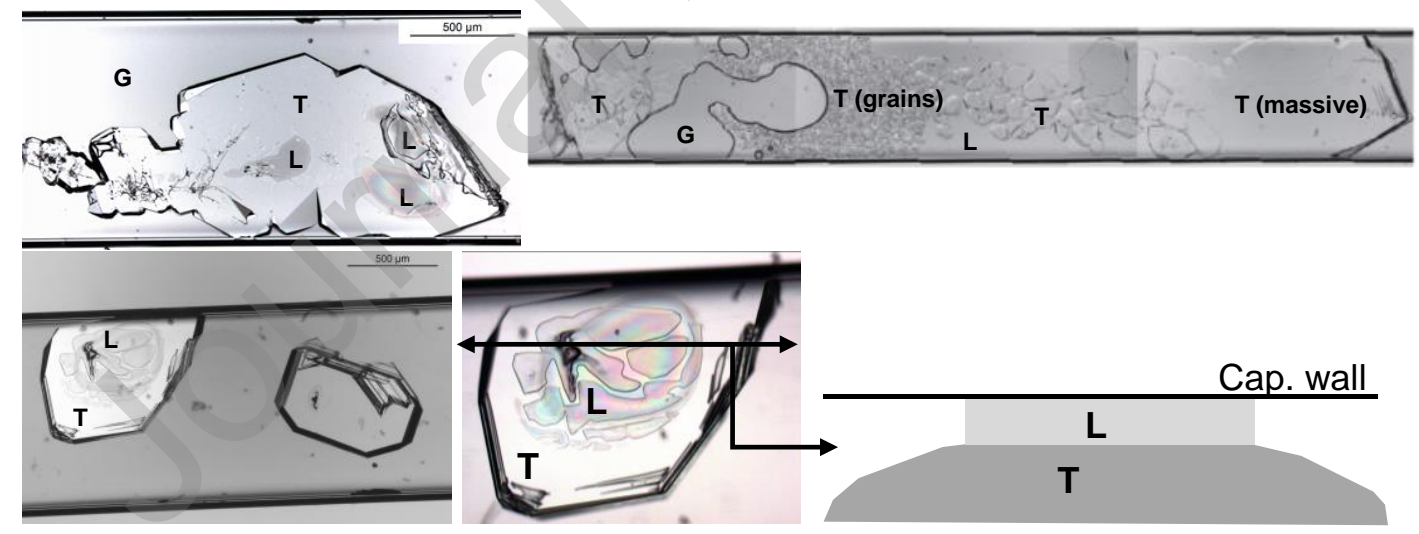

Figure 2. Upper, illustration of the possible mineralogical habits of thenardite during the preparation process (G: air; L: aqueous solution; T: thenardite). Lower, water (L) sandwiched in-between massive thenardite $(\mathrm{T})$ and capillary walls. Photographs are top viewed, and the sketch is drawn as a sideview.

In the following, the study focuses on the evolution of this thenardite-solution assemblage according to three further procedures.

- water refilling in the thenardite-bearing microcapillary and subsequent re-drying by "passive" evaporation in the climate chamber at controlled $\mathrm{RH}$.

- thermal change by cooling down to negative temperature (in ${ }^{\circ} \mathrm{C}$ ).

- "capillarization" of the occluded liquid and the associated superheating. 


\section{Results}

\subsection{Fracturing of the silica container: drying pathway}

The milli-Q water refilling obviously caused a partial dissolution of the massive thenardite (Fig. 3a) followed by a rapid crystallization of a large number of mirabilite crystals (elongated strips) in the free space around the thenardite (Fig. 3b). In a third step, the water-air meniscus retreats due to the air dryness, evidencing a reevaporation of the refilling water which first promotes the mirabilite precipitation, and after a while promotes its dehydration to thenardite micro-crystals (Fig. 3c).

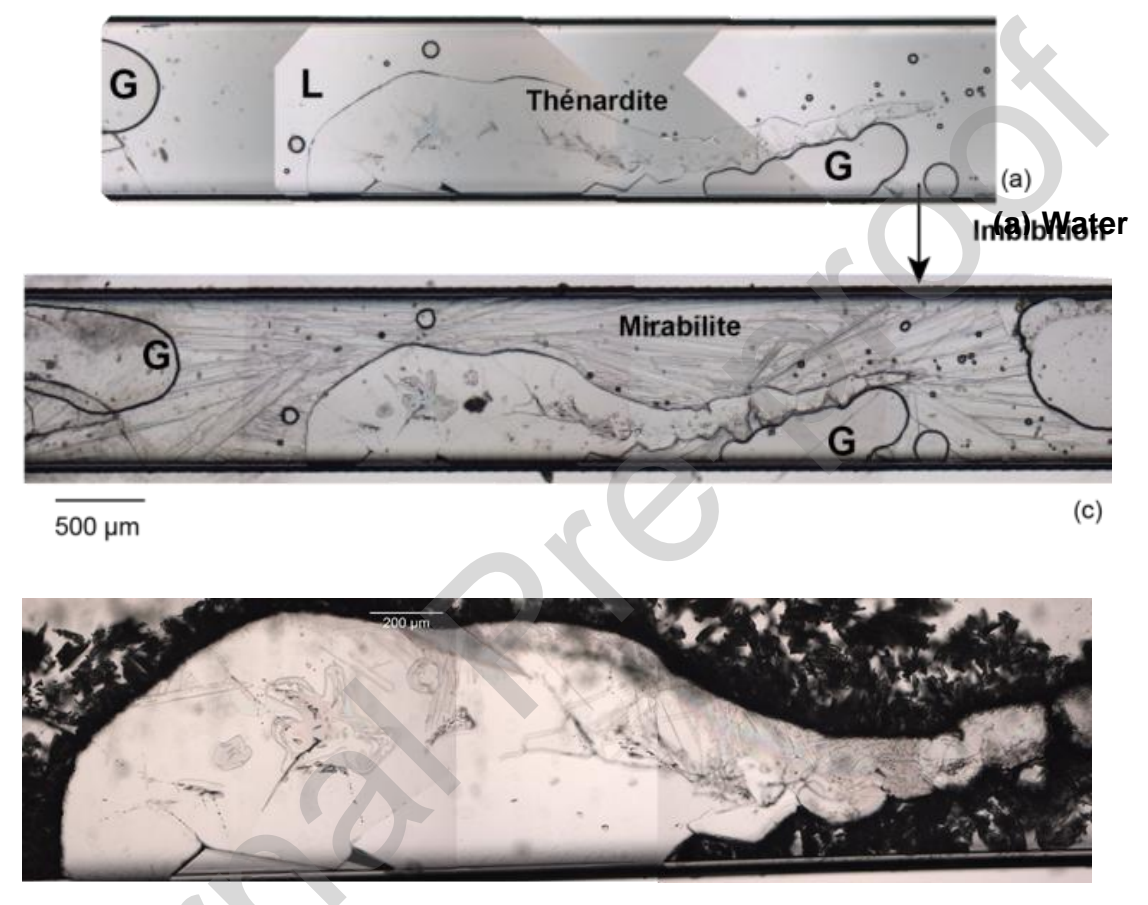

Figure 3. Water refilling (a), then first mirabilite precipitates (b), further dehydration into micro-grains of thenardite due to water re-evaporation (c). G: air, L: liquid.

A second refilling stage of the tube followed, causing the rapid dissolution of the thenardite micro-grains and subsequent re-precipitation of mirabilite in the free space (Fig. 4, step 2). But the peculiarity of this second stage is that mirabilite also appeared as elongated strips within the water layer sandwiched in the narrow space between thenardite and the capillary wall. At this moment, the glass wall fractured above the massive crystal of thenardite (Fig. 4, step 2), making clear that the crystallization pressure was damaging the wall. 


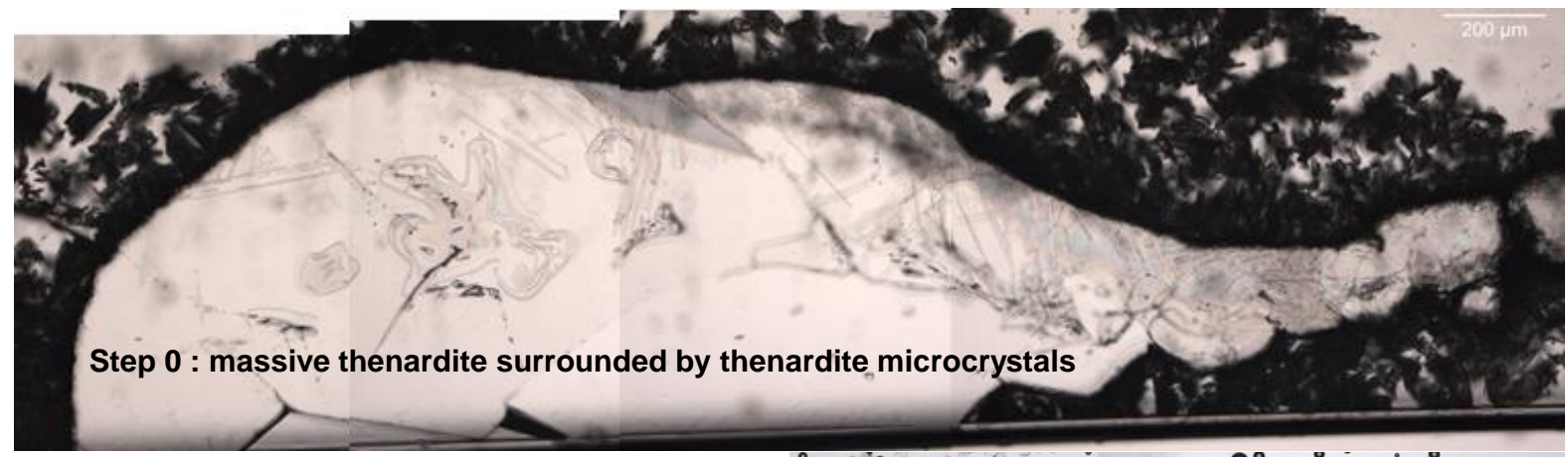

Step 1 : water refilling likely with cavitation of water trapped within micro-crystallites (see text).
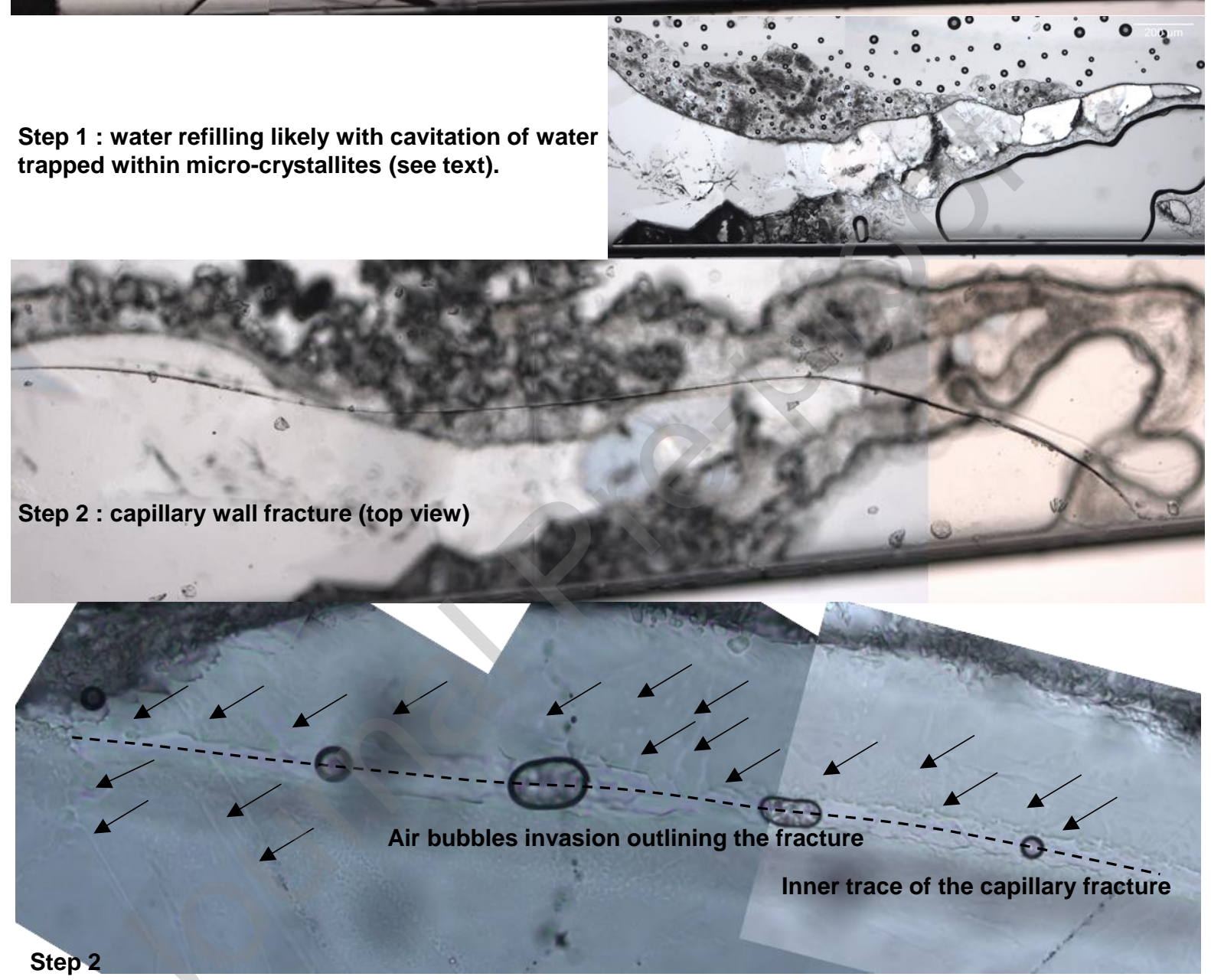

with overgrown mirabilite.

Figure 4. Second imbibition process pumping in pure water inside a complex texture associating massive crystals and crystal grains, leading to fracturing of the host tube.

This experiment was repeated over six filling-drying-refilling sequences on the same capillary tube, leading to the same series of observations including the tube fracturing (Figure 5). The sequence clearly showed that the massive thenardite dissolved partly at each refilling, and the fracture always takes place above the thenardite massif (Fig. 5). Interestingly, in the left area close to the extremity of the tube, it is quite clear that no mirabilite is present in the "free space", meaning only a mirabilite "sandwich" as elongated strips, again, can account for the fracturing (Fig. 5). 


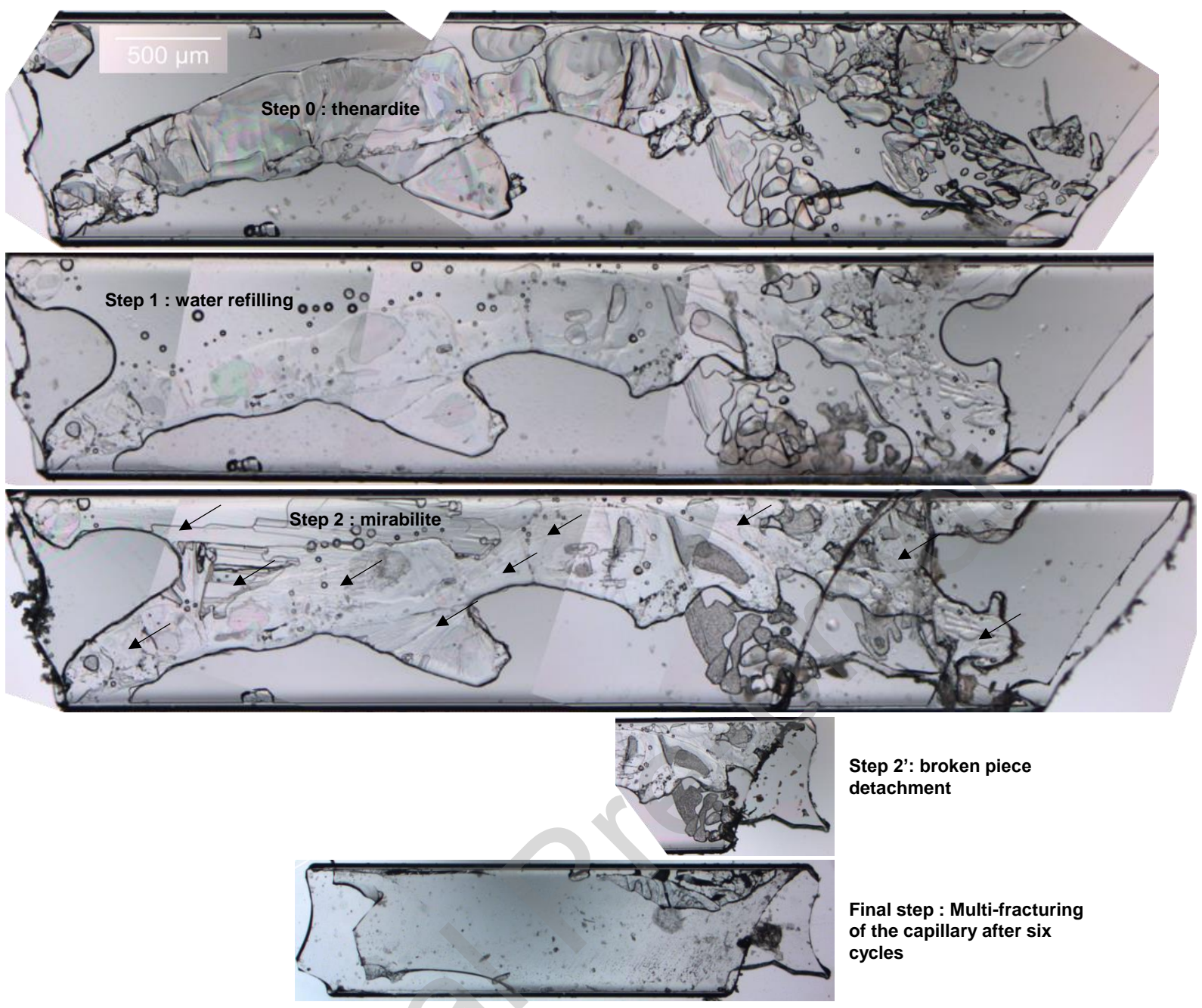

Figure 5. Mirabilite-driven multi-steps fracturing by drying-wetting repeated cycles.

\subsection{Fracturing of the container and of the growing crystal: cooling pathway}

A second series of experiments was performed using a decreasing temperature to trigger the crystallization of the hydrated phase of $\mathrm{Na}_{2} \mathrm{SO}_{4}$, either heptahydrate or mirabilite, in a microcapillary filled with a large amount of thenardite at equilibrium with an aqueous (saturated) solution. According to the well-known phase diagram (Fig. 1B, see also the 'discussion' section), a decreasing temperature increases the supersaturation of a thenardite-saturated solution with respect to hydrated $\mathrm{Na}_{2} \mathrm{SO}_{4}$. The decreasing temperature, especially below $0^{\circ} \mathrm{C}$, is commonly expected to promote heptahydrate rather than mirabilite (e.g., [28-29]), and we were not able to identify the secondary phase that crystallizes during the course of our experiments. Both hydrates are able to create damage even if heptahydrate is less and less apt to do it with temperature since the thenardite-to-heptahydrate supersaturation diminishes with heating (as illustrated by the length of the vertical black arrows in Fig. $6 \mathrm{~A})$. The initial situation is made of an in-capillary multiphase assemblage composed by a piece of massive thenardite contacting a large volume of aqueous solution saturated at room temperature $\left(20^{\circ} \mathrm{C}\right)$ with respect to thenardite. 
The first cooling experiment was performed in a cylindrical capillary with the massive thenardite in the shape of a 'blocking plug' at the end of the microcapillary (Fig. 6). A film of solution is assumed to fill in the annular space around the thenardite plug, what is not visible but has been shown previously [30-32]. Then, the temperature is cooled down what increases the supersaturation ratio between thenardite and both hydrates, heptahydrate and mirabilite. However, due to the rapid cooling rate $\left(5^{\circ} \mathrm{C} / \mathrm{mn}\right)$, the concentration of the solution is assumed not to change despite thenardite becomes more soluble with cooling, and so it kept constant at the concentration determined by the $20^{\circ} \mathrm{C}$ equilibrium (see horizontal light black arrow, Fig $6 \mathrm{~A}$ ). At $-11^{\circ} \mathrm{C}$, namely $3.1^{\circ} \mathrm{C}$ above the freezing curve (Fig. $\left.6 \mathrm{~A}\right)$, the hydrated $\mathrm{Na}_{2} \mathrm{SO}_{4}$ starts to precipitate, triggering a brutal and large silica tube fracturing (Fig. $6 \mathrm{~B}$, lower panel). At these conditions, the thenardite-to-heptahydrate crystallization pressure is $42.2 \mathrm{MPa}$, while the thenardite-to-mirabilite reaches $56.1 \mathrm{MPa}$. Both values are large enough to induce solid damage. 


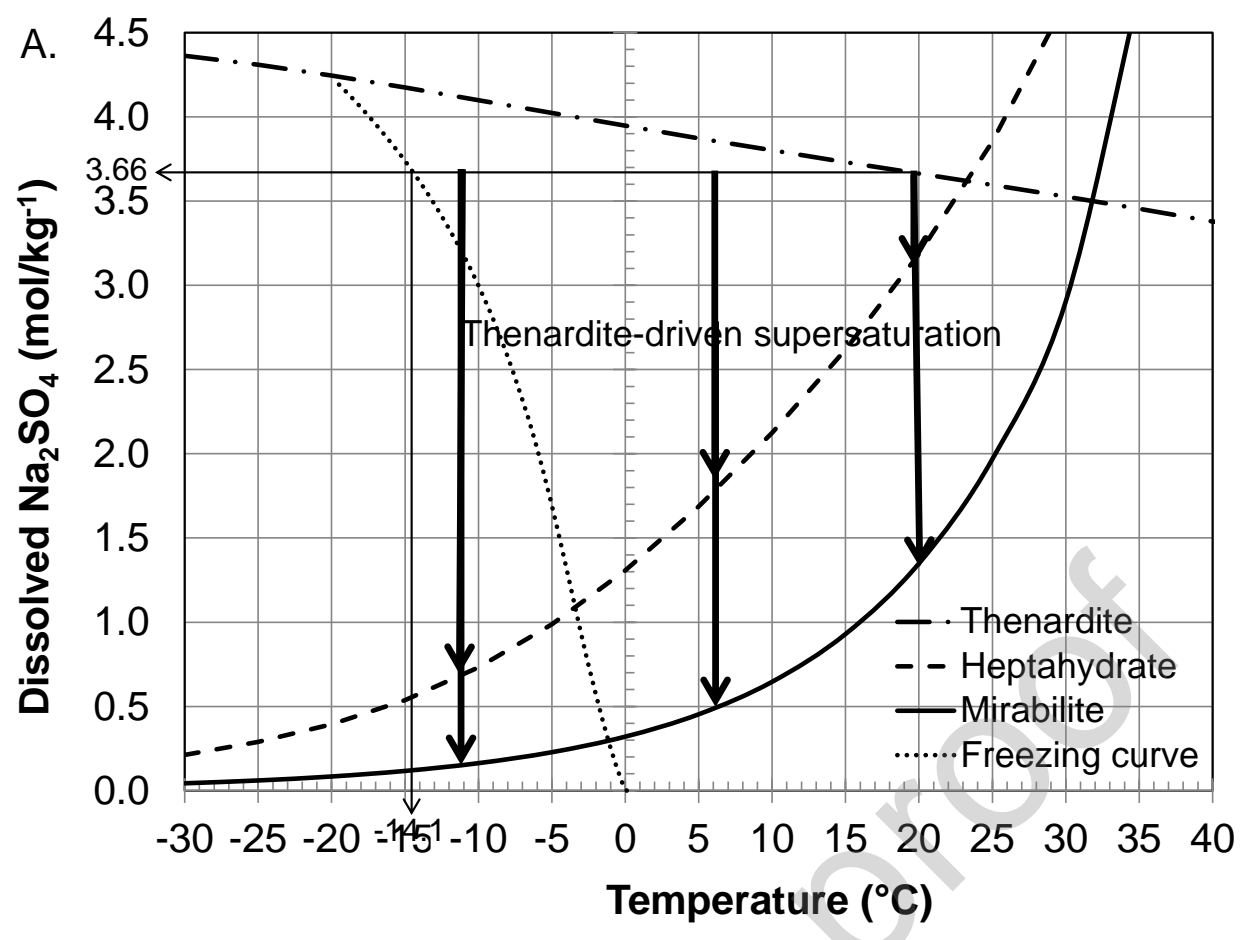

B.

Solution trapped in between thenarditeland microcapillary
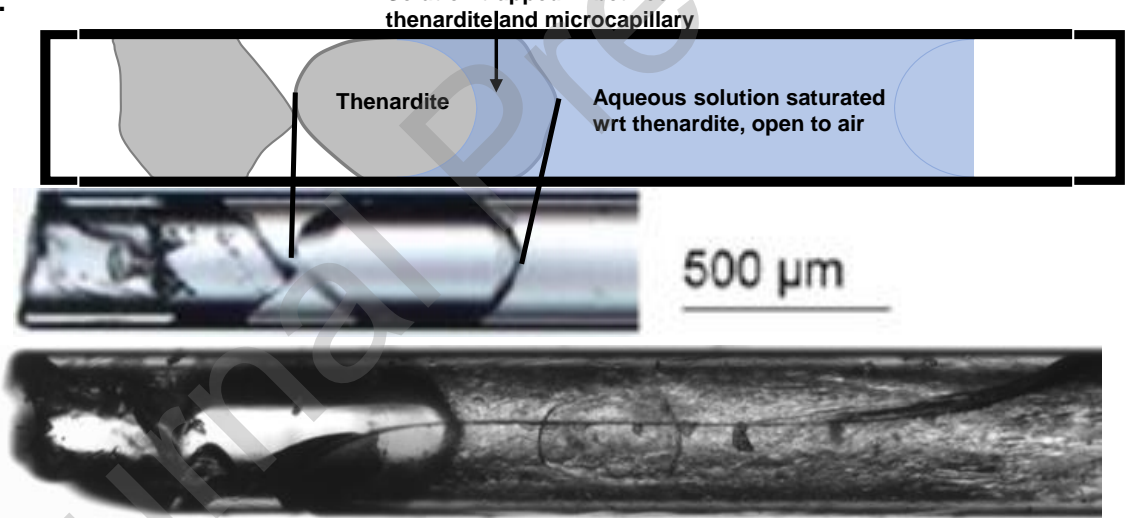

Figure 6. A, Solubilities of thenardite, heptahydrate and mirabilite, and freezing curve of the saturated solution at various temperatures, calculated with Pitzer correction according to the ColdChem database [24]. The freezing point for a thenarditesaturated solution at $20^{\circ} \mathrm{C}$ is reported (light vertical black arrow), as well as the supersaturation with respect to heptahydrate and mirabilite (thick black arrows) for the three characteristic temperatures of the experiment (see text). B, Hydrous $\mathrm{Na}_{2} \mathrm{SO}_{4}$-driven fracturing of the silica capillary. On the lower panel, the right extremity of thenardite (circled) shows a slight darkening that may be interpreted as a heptahydrate/mirabilite precipitation in the annular space between thenardite and microcapillary. We were not able to capture the triggering zone of the fracturing.

A second cooling experiment was carried out in a rectangular capillary tube, without free liquid in the capillary. This time, the massive thenardite coexists with only a water layer, micrometric-thick, sandwiched in certain area in-between thenardite and the silica walls (Fig. 7 upper panel, see also section 2.2 and Fig. 2). 

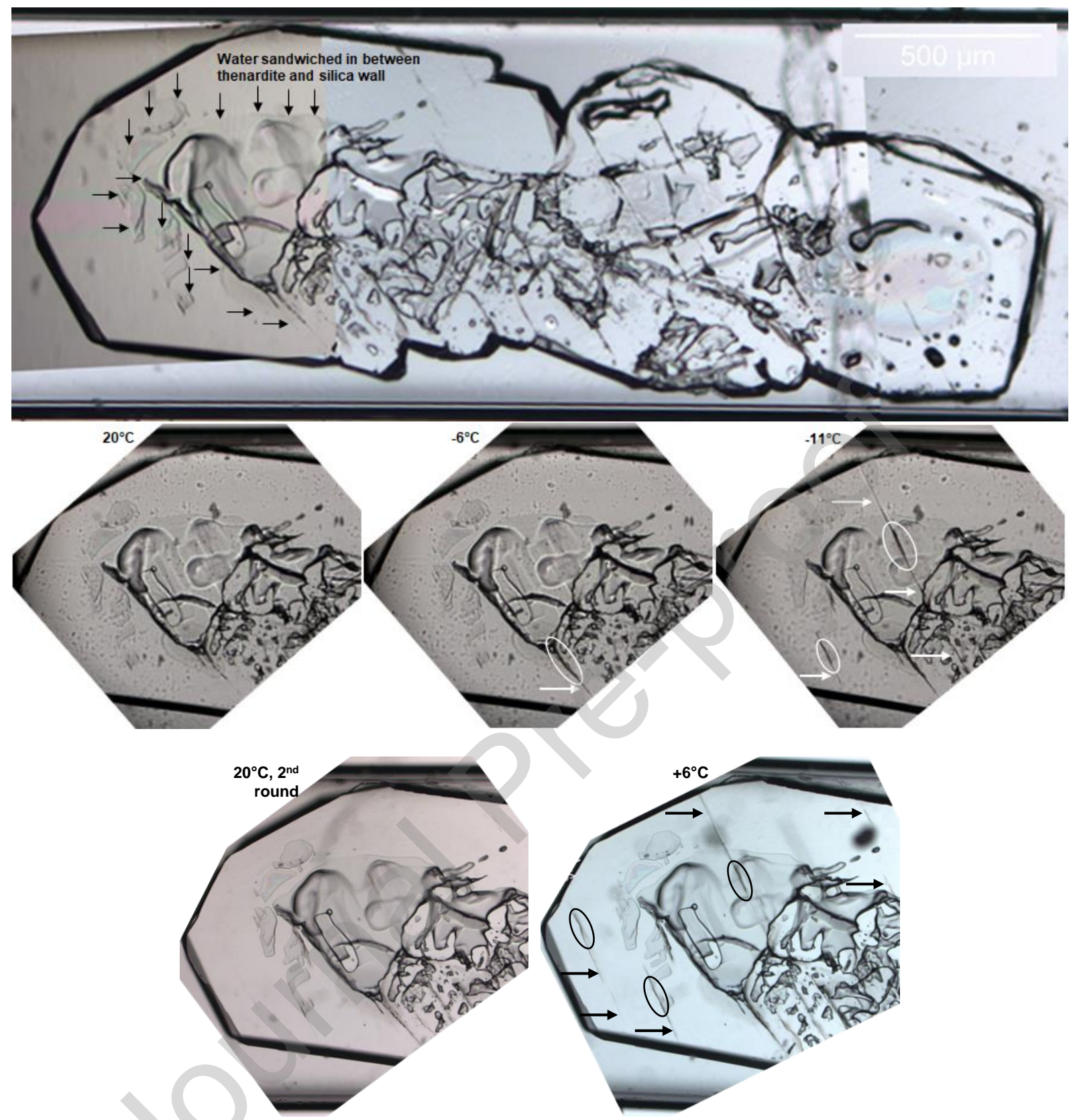

Figure 7. Fracturing of the thenardite plug likely due to hydrate growth in the water layer trapped in between thenardite and silica wall. Upper panel, at room temperature, water layer trapped above the thenardite. Middle panel, the fractures are pointed to by white arrows, and the white circles outline darkening zones presumably due to hydrate growth. Lower panel, second sequence of fracturing after reheating. Black arrows and circles outline the fractures and the precursor darkening zones, respectively.

The sequence of observations highlights the fracturing happening inside the thenardite (at $-6^{\circ} \mathrm{C}$, intensifying at $-11^{\circ} \mathrm{C}$, Fig. 7). It is preceded by a localized darkening appearing immediately before the fracture happens with the hydrated $\mathrm{Na}_{2} \mathrm{SO}_{4}$ slightly visible crystallization (Fig. 7, middle panel). These two temperatures are unambiguously above the freezing temperature at the solution concentration (3.66 mol. $\mathrm{kg}^{-1}$, which is the saturation concentration at $20^{\circ} \mathrm{C}$; Fig. $6 \mathrm{~A}$ ). Interestingly, 
when back at ambient conditions, the fractured thenardite crystal clearly healed (Fig. 7, lower panel) to reappear at further cooling, this time at $+6^{\circ} \mathrm{C}$ (Fig. 7, lower panel) occurring at both prior and new localizations. The crystallization pressure then reaches $31.9 \mathrm{MPa}$ if mirabilite crystalizes, and $19.8 \mathrm{MPa}$ if this is heptahydrate. It is again strictly impossible that ice crystallization accounts for this in-thenardite fracturing. The increased temperature to initiate fracturing is a possible consequence of the first round that makes the thenardite more fragile. Also interesting is the observation that the fractures then-formed during the second round of cooling never healed at later reheating: the fracturing was therefore irreversible.

These experiments are pleading that the crystallization pressure generated by the growth of one hydrated $\mathrm{Na}_{2} \mathrm{SO}_{4}$ phase inside a water layer can damage any of the two solids that limit the layer, either the top capillary wall or the bottom thenardite crystal. It is also interesting to note that the damage may be reversible. We note that the reversible fractures were only observed in the thenardite massive crystal, at the beginning of the damaging cycle. We did not analyze in detail this process, but we may speculate that those crystals created by grain-grain coalescence (see section 2.2) might retain structural heterogeneities, as can be visible in the next section using crossed polarized light (see Fig. $8 \mathrm{C}$ below). The grain-grain contacts would be a zone of accumulation of defaults that may contribute to lower the constraints required to trigger fracturing (sub-critical process). The early crevice opening may sometimes have been limited to a reversible crack, while later constraints led to an irreversible damage.

\subsection{Fracturing of the growing crystal: cavitation pathway}

A last round of experiments was carried out wherein the massive thenardite was this time located at two opposite ends of a long microcapillary. In-between the two thenardite plugs, a long water column is confined, the thermodynamic state of which is controlled by the nano-capillary menisci located around each of the thenardite plugs (e.g., [30-32]). According to capillarity law, all the water trapped behind these nano-menisci retains a capillary Laplace pressure (lower than the atmospheric's, can reach negative values), supersolubility properties, and a limited lifetime (e.g., [3032]). This capillary tube was regularly observed for two years, showing an "immobile" thenardite-liquid coexistence, while the aqueous solution was obviously at chemical equilibrium with thenardite.

A very interesting sequence concluded this long-term observation. The trapped water cavitated (or boiled) at distance from both ends (Fig. 8B), demonstrating that most of the trapped water is metastable, as previously observed (e.g., [30-32]). Some times after the cavitation, we observed the development of fractures in the thenardite, while clues of new solid presence was recorded though not visible directly (Fig. $8 \mathrm{C}$ ). At the crossing point of the different directions of the fracturing, a mass of solid can be distinguished, especially with crossed polarized light, that can be either newly formed thenardite or mirabilite. 


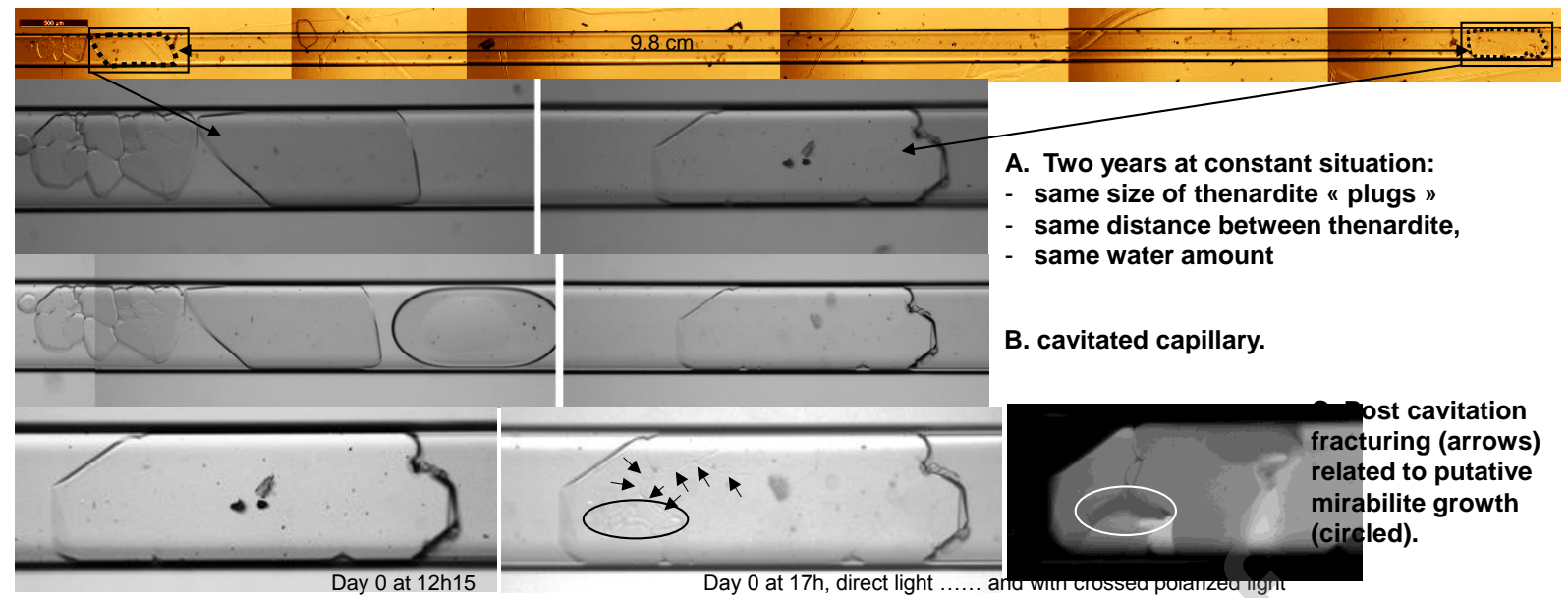

Figure 8. Capture of the sequence of events from initial capillary-type situation in dual pore system (nano-menisici coexisting with a large pore body; top photo) to cavitation (B), and salt damage (C).

4. discussion

4.1 Volume change

1.2 One scenario of salt damage is to assume that the volume change at the phase transition, when positive, contributes to fracturing due to the confining space of the host pore, as for ice freezing in a filled bottle. In the present drying (section 3.1) and cooling (section 3.2) experiments, it is obvious that there was largely room for the heptahydrate or mirabilite to grow out of any space limitation. It means that the existing reactional volume effective at hydration $(\Delta \mathrm{V} \sim+10 \%$, depending on the temperature; similar to the $\Delta \mathrm{V}$ at freezing), cannot explain the fracturing observed. Even with the experiments with limited amount of fluids (second cooling experiments, section 3.2; cavitation experiment, section 3.3), the restricted spaces (when visible) do not appear entirely filled before fracturing, meaning the lateral spaces are still available for mineral growth.

1.3 The experiments amply demonstrate that the volume variation is not the cause of the mechanical constraints, actually in agreement with the common sketch. The only experiment that could be put into question on that respect is the first cooling one, where fracturing develops while the hydrate invades most of the capillary volume. We were not able to localize the triggering zone of the fracturing, so we cannot exclude that the total volume of solid is larger than the available volume.

\subsection{Role of thenardite precursor}

The drying experiment (section 3.1) makes clear that thenardite micro-grains are very prone to dissolution at each refilling, creating locally supersaturation in the solution with respect to mirabilite. A solution at equilibrium with thenardite $\left(3.66 \mathrm{~mol} . \mathrm{kg}^{-1}\right)$ is supersaturated with respect to mirabilite $\left(1.35 \mathrm{~mol}_{\mathrm{kg}}{ }^{-1}\right)(\mathrm{Fig} 9)$, that corresponds to a crystallization pressure of $13.8 \mathrm{MPa}$ at $20^{\circ} \mathrm{C}$, according to the following expression (e.g., [11]):

$$
\Delta \mathrm{P}_{\text {crystallization }}=v R T / \mathrm{V}_{\mathrm{m}} \cdot \ln \left(\mathrm{a} / \mathrm{a}_{0}\right)
$$


where $\Delta \mathrm{P}_{\text {crystallization }}$ is the overpressure with respect to the pressure of the solution $\left(\Delta \mathrm{P}_{\text {crystallization }}=\mathrm{P}_{\text {growing crystal }}-\mathrm{P}_{\text {liquid }}\right), v$ is the stoichiometric number of solutes released by the dissolution of the salt, $R$ the ideal gas constant, $T$ the absolute temperature, $V_{m}$ the molar volume of the solid phase (here mirabilite), $a_{0}$ and a are the solute activities of the saturated and the supersaturated solutions.

Equation (1) writes for the thenardite-controlled mirabilite supersaturation [25]:

$$
\begin{aligned}
& \Delta \mathrm{P}_{\text {crystallization }}=3 \mathrm{RT} / \mathrm{V}_{\text {mirabilite. }}\left[\ln \left(\mathrm{m}_{\text {equil-thenardite }} \text { at } 20^{\circ} \mathrm{C} / \mathrm{m}_{0, \text { equil-mirabilite }}\right)+\ln \left(\gamma_{ \pm} / \gamma_{ \pm, 0}\right)+\right. \\
& \left.10 / 3 \cdot \ln \left(a_{w} / a_{w, 0}\right)\right]
\end{aligned}
$$

where $\mathrm{m}$ and $\mathrm{m}_{0}$ are molalities, $\gamma_{ \pm}$and $\gamma_{ \pm, 0}$ are the mean activity coefficients of the aqueous electrolyte, $a_{w}$ and $a_{w, 0}$ the water activities at the thenardite $\left(a t 20^{\circ} \mathrm{C}\right.$ ) and mirabilite saturation respectively (Fig. 9).

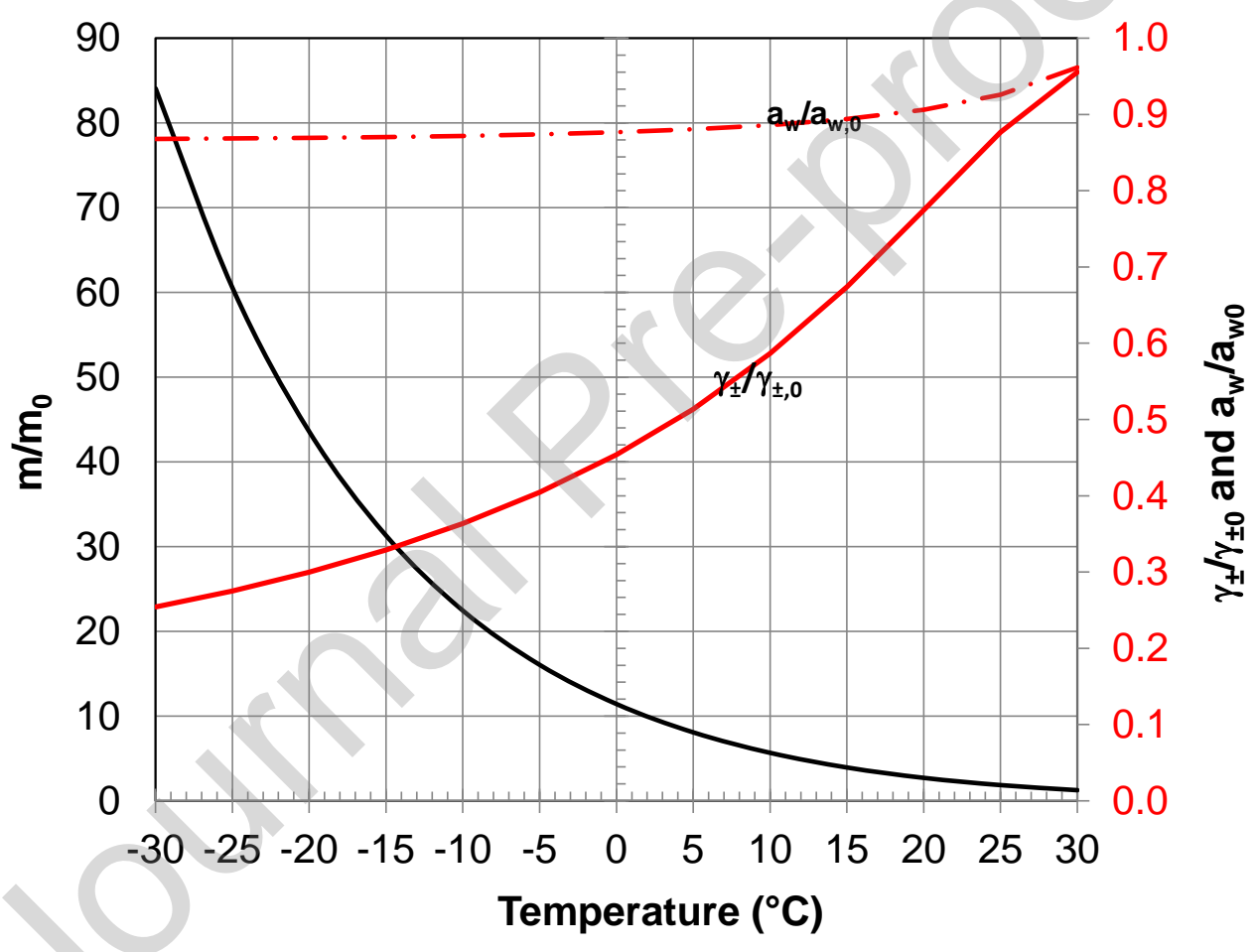

Figure 9. Ratio from thenardite values over mirabilite's, on the sulfate ion molality ( $m$ $\left./ \mathrm{m}_{0}\right)$, mean activity coefficient $\left(\gamma_{ \pm} / \gamma_{ \pm, 0}\right)$, and water activity $\left(\mathrm{a}_{\mathrm{w}} / \mathrm{a}_{\mathrm{w}, 0}\right)$, calculated with Pitzer correction according to the ColdChem database [24].

This 13.8 MPa value is lower than the flexural strength of pure borosilicate glass (34$69 \mathrm{MPa}$ ), but commensurable to the 3-7 MPa tensile strength given by microcapillary manufacturers (Scientific Glass Laboratories, Schott Duran ${ }^{\circledR}$ ) for tubing thinner than $2 \mathrm{~mm}$.

In the cooling experiment (section 3.2), the supersaturation with respect to heptahydrate and mirabilite grows with the decreasing temperature at constant composition of solution (Fig. 9 left). At $-11^{\circ} \mathrm{C}$, slightly above the freezing curve, the crystallization pressure due to mirabilite growth is $56.1 \mathrm{MPa}(42.2 \mathrm{MPa}$ if heptahydrate growth) and the cylindrical container is broken. With the rectangular 
capillaries used for the second cooling experiments, it is not clear why the container resisted better, while the thenardite broke out despite it was previously not affected. The most straightforward explanation is about the nucleation mode of mirabilite, either onto thenardite by hetero-epitaxial growth or within the separating solution layer by a homogeneous-like nucleation process. In the first case, the crystallization pressure developed until the silica broke out; in the second case, the two opposite solids, thenardite and silica were put under constraints, and the most fragile broke first. Scherer [9] proposed different scenarios directly leading to these two varied situations (see especially his Figs 5 and 7). The chemical state of the surface (water repellency, crystallographic features, disjoining pressure parameters) thus becomes a major controlling parameter, what was convincingly argued by Desarnaud et al. [15].

In the cavitation experiment (section 3.3), the saturation in the solution with respect to thenardite is enhanced by the additional supersolubility caused by the capillary pressure in the trapped liquid. To evaluate the latter pressure, one may use the metastability lifetime as a first approximation (e.g., [32]). With a lifetime of two years, the Bouzid et al.'s procedure would reveal that the tension was around -68 MPa, and so a supersolubility amounting to 1.05 [30]. The corresponding crystallization pressure (eq (1)) is therefore 1.6 MPa if the growing mineral is thenardite or 15.4 $\mathrm{MPa}$ if it is mirabilite (see also section 4.4).

\subsection{Role of restricted spaces / water films}

In the cooling (section 3.2) and cavitation (section 3.3) experiments, the crystal growth that causes silica or thenardite fracturing took systematically place inside the 'restricted' zones. In that sense, the pre-grown thenardite (or any other salt, indeed) is a major player by creating the required finite spacing wherein the solid-film-solid interphase is instrumental for the crystallization pressure to happen. In that sense, the drying-wetting cycles allowing the pre-filling of pore spaces is an absolute prerequisite.

The specificity of the cavitation experiment (section 3.3) is the extreme thinness of water films located between the thenardite and the pore wall (e.g., [30,32]). Due to external low $\mathrm{RH}$, these films acquire strong capillary properties accompanied with a significant supersolubility. After cavitation and its brutal change of the liquid pressure, a supersaturation appears, driving the salt precipitation and leading to damage. The supersaturation is moderate if thenardite precipitates $(\mathrm{S}=1.05 ; \Delta \mathrm{P}=1.6 \mathrm{MPa})$, while if mirabilite grows, the supersaturation reaches 2.85 and the $\Delta \mathrm{P}$ amounts to $15.4 \mathrm{MPa}$. Additionally, cavitation is accompanied by acoustic emissions and therefore release of elastic energy, which provides supplementary activation energy to trigger salt nucleation.

\subsection{Cooperativity between capillary tensile water and crystallizing compressive salt}

With the cavitation experiment (section 3.3), a new mechanism of sudden fracturing can be proposed, in a pathway without any apparent cause: no change of temperature and no drying, while the phase transition really happens. Furthermore, as it depends on the cavitation process, its timing is statistically variable, also 
depending on local perturbations possibly supplying the activation energy to cross the metastability barrier. Unfortunately, we cannot give clear clues about the nature of the solid that grows after cavitation. But our results are in agreement with the onlythenardite fracturing process [19] despite through a different mechanism. These latter authors argued from the pore-size controlled solubility, while we are proposing the cavitation process.

In terms of poromechanics, the prior tensile effort due to nano-menisci may exert constraint on the local solids (thenardite plug and silica tube wall). This mechanical constraint anticipates the crystallization pressure effect that develops after the cavitation. This sequence of tension-compression may increase the damage associated to crystallization pressure, related to a fatigue effect, as was previously illustrated with polycarbonate membrane [33] and silicon wafers [34-35].

Moreover, it is hypothesized that salts cause more damage to rocks with a large proportion of micropores connected with macropores $[1,7,21]$. This classic model states that the micropores promote an enhanced solubility due to pore size effect (e.g., [36-39]), which corresponds to a supersaturation when it comes to neighboring macropores. The unsolved question of this model is the time required for the Fick diffusion to impose the same composition throughout the whole porous network. Our present model could offer an alternative explanation for these observations. The micro-macropores network can promote capillarity when drying conditions are imposed. It opens up the tension-compression cycle described above.

\section{Conclusion}

The classic sketch of salt damage by crystallization pressure was directly observed during the present experiments. Using three different driving forces (drying, cooling, capillarity), we were able to build the supersaturation needed for the crystals growing in pores to break its container. The experiments were performed in silica microcapillaries and led, for the first time to our knowledge, to the direct observation of the capillary fracturing. Furthermore, and in agreement with the light put on the disjoining film [15], the damage (i.e., fracturing) during drying-wetting cycles, can occur on any of the two solids (here, the massive thenardite and the silica wall) that sandwich the aqueous solution layer wherein the new solid is growing. And this is also a new observation never recorded up to now in the literature. In agreement with our discussion, the exact nucleation-growth mechanism should be important, especially the role played by the existing solid surfaces at the pore scale to initiate or not the growth, what would define on which solid the growing solid can exert a constraint.

Apart the direct observations of the functioning of salt damage, the present paper demonstrates that, at constant temperature and without any drying-driven water loss, a significant volume of water can be capillarized in large pores on relatively long time lengths before cavitation occurs, leading to a sudden supersaturation apt to significant fracturing. Cavitation experiment is a new mechanism to induce salt damage, never described in the literature to our knowledge. This is also a very unique example, to our knowledge, of a brutal transformation at constant temperature for a system "immobile" for two years, without significant drying rate. Actually, according to what we discussed, the supersolubility resulting from the metastability of 
capillary water trapped in strongly dual pore system, can provide the triggering "chemical excess" required for crystallization pressure. Moreover, Hulin and Mercury [31] demonstrated recently that capillarity can be cyclically recreated by internal processes in dual pore media. It means that this cavitation-driven transient mechanism, may be repeated several times, dramatically increasing the efficiency of the fatigue mechanism and the final damage at the rock scale.

More generally, the drying-wetting cycles, as expected for a stone or a soil exposed to natural atmosphere under changing climate, complexify the multiphase filling within the pores network. They can contribute to install the micro- to macro-pore situations imaged in this paper, even starting from possibly unfavorable initial situation like having mainly large pores (sketched by the large capillary tube) and/or dilute infilling solution. Actually with time and repetitions of drying and wetting stages, the first anhydrous precipitates can take place and strongly modify the inner geometries of the pore network, fabricating zones with water layers that can localize the damaging constraints.

Eventually, the importance of the metastable situations (capillary-driven superheating, drying/cooling-induced supersaturation) has been largely stressed throughout this work. Interestingly, they can cooperate in multiphase pores, and also appear inside rocks through time, secondary phase transitions, varying climate conditions. The pore sizes distribution (macro/micro-pores ratio, presence of nanopores), as well as the geography of those sizes (pore throats to pore bodies arrangements), are decisive constraints to result into salt damage. And we can outline that these geometrical constraints can evolve in a given rock through time and climate conditions.

Despite these interesting advances allowed by a direct observation of a wellcontrolled multi-scale pore system, our experiments showed limitations. Sometimes, phase transitions and fracturing occurred very quickly, while in some other cases, with comparable driving forces, the advancement appeared much slower. The present experiments can be much better controlled, using nano/micro-channels networks fabricated at hand by silicon etching techniques imported from nanofluidics technologies. Such nano-models would present restricted spaces of perfectly controlled geometries, infilled with aqueous solution of controlled composition, in presence of air of controlled $\mathrm{RH}$, all of this at controlled temperature. The chemical state of inner walls can also be closely controlled in those nano-models. Exact measurements of the role of each parameter acting in the chemo-mechanical couplings at the pore scale is therefore the next target.

Acknowledgments.

This work has received support from the French Agency for Research (Agence Nationale de la Recherche, ANR) through the grant CONGE BLAN-610-01, the Equipex Planex ANR-11-EQPX-36 and the labex Voltaire ANR-10-LABX-100-01. LM is indebted to Prof. Michael Steiger (University of Hamburg) to have very liberally sent him all the experimental data about sodium sulfate salts that he collected for his own studies. We are also grateful to two anonymous reviewers and the handling editor who helped us to improve the initial version of the manuscript. 
Appendix

The ion specific interaction model developed by Pitzer [40-41] enables the determination of the activity coefficients $\gamma_{j}$ in the bulk electrolyte. Most often, strong electrolytes fully dissociate in one cation and one anion. In the case of a completely dissociated 1:2 electrolyte $\mathrm{M}_{2} \mathrm{X}$ (like $\mathrm{Na}_{2} \mathrm{SO}_{4}$ ) in a binary aqueous solution and according to [40], the individual activity coefficient of the cation $\mathrm{M}^{+}$is given by (a symmetrical expression can be written for the activity coefficient of the anion $\mathrm{X}^{2-}$ ):

$\ln \gamma_{M}=F+m_{X}\left[2 B_{M X}+\left(m_{M}+m_{X}\right) C_{M X}\right]+m_{M} m_{X} C_{M X}$,

$F=-A^{\phi}\left[\frac{\sqrt{I}}{1+b \sqrt{I}}+\frac{2}{b} \ln (1+b \sqrt{I})\right]+m_{M} m_{X} B^{\prime}{ }_{M X}$,

$A^{\phi}=\frac{1}{3}\left(\frac{2 \pi N_{a} d_{w}}{1000}\right)^{1 / 2}\left(\frac{e^{2}}{\varepsilon_{w} k_{b} T}\right)^{3 / 2}$

$m_{M}+m_{H^{+}}=2 m_{X}+m_{O H^{-}}$, with $m_{H^{+}}, m_{O H^{-}} \ll m_{M}, m_{X}$,

$I=\frac{1}{2} \sum_{j} z_{j}^{2} m_{j}=\frac{1}{2}\left(m_{M}+m_{H^{+}}+4 m_{X}+m_{O H^{-}}\right) \approx \frac{1}{2}\left(m_{M}+4 m_{X}\right)$,

where $I$ is the ionic strength (in mol $\mathrm{kg}^{-1}$ ), $b$ an empirical parameter with a value of 1.2 and $A^{\phi}$ the Debye-Hückel coefficient (which can be computed over a wide range of temperatures and pressures using the "ThermoZNS" computer code; [43], including the negative temperatures $\left({ }^{\circ} \mathrm{C}\right)$ and pressures. The Debye-Hückel coefficient depends on the density $d_{w}$ (in $\mathrm{kg} \mathrm{m}^{-3}$ ) and the dielectric constant $\varepsilon_{W}$ (in $\mathrm{F} \mathrm{m}^{-1}$ ) of pure water. The subscript "M" denotes a cation (the monovalent $\mathrm{Na}^{+}$cation ion in the present case), " $\mathrm{X}$ " denotes an anion (the divalent $\mathrm{SO}_{4}{ }^{2-}$ anion in the present case), and $N_{a}$ is the Avogadro number $\left(6.02 \times 10^{23}\right.$ compound $\mathrm{mol}^{-1}$ ).

$B_{\mathrm{MX}}$ and $B_{\mathrm{MX}}^{\prime}$ describe the interaction of pairs of oppositely charged ions, which are defined as explicit functions of the ionic strength by:

$$
\begin{aligned}
& B_{M X}=\beta_{M X}^{0}+\beta_{M X}^{1} g\left(x_{1}\right)+\beta_{M X}^{2} g\left(x_{2}\right), \\
& x_{1}=\alpha_{1} \sqrt{I}, x_{2}=\alpha_{2} \sqrt{I} \\
& g(x)=-2\left[1-(1+x) \mathrm{e}^{-x}\right] / x^{2} \\
& B_{M X}^{\prime}=\beta_{M X}^{1} g^{\prime}\left(x_{1}\right) / I+\beta_{M X}^{2} g^{\prime}\left(x_{2}\right) / I
\end{aligned}
$$


$g^{\prime}(x)=-2\left[1-\left(1+x+\frac{x^{2}}{2}\right) \mathrm{e}^{-x}\right] / x^{2}$,

where $\beta_{\mathrm{MX}}^{0}, \beta_{\mathrm{MX}}^{1}, \beta_{\mathrm{MX}}^{2}$ are the Pitzer parameters, and $\alpha_{1}=2$ for $1: 2$ electrolytes. In general, $\alpha_{2}=0$ for $1: 2$ electrolytes but [44] use the non-zero value $\alpha_{2}=0.5$ in their ColdChem thermochemical database. The term $C_{\mathrm{Mx}}$ describes ternary short range interactions between two cations and one anion, and one cation and two anions. It is expressed by:

$C_{M X}=0.5 C_{M X}^{\phi}$

Therefore, up to four coefficient values, $\beta_{\mathrm{MX}}^{0}, \beta_{\mathrm{MX}}^{1}, \beta_{\mathrm{MX}}^{2}$ and $C_{\mathrm{MX}}^{\phi}$, are needed to predict the activity coefficient using the Pitzer theory for 1:2 electrolytes.

These coefficient values are available in Pitzer databases for a number of electrolytes at subzero temperatures [24,45-46]. We selected the ColdChem database of [44] which is an improvement of the older ones and can be used straightforwardly with the geochemical calculation code PhreeqC-3 [47].

\section{REFERENCES}

[1] Wellman H.W. and Wilson A.T. (1965) Salt weathering, a neglected geological erosive agent in coastal and arid environments. Nature 203, 1097-1098.

[2] Goudie A. and Viles H. (1997) Salt weathering hazards. John Wiley \& sons, Ltd, England.

[3] Cooke R. U. (1981) Salt weathering in deserts. Proc. Geol. Ass. 92 (1), 1-16.

[4] Prebble M.M. (1967) Cavernous weathering in the Taylor Dry Valley, Victoria Land, Antartica. Nature 216, 1194-1195.

[5] Matsuoka N. (1995) Rock weathering processes and landform development in the Sør Rondane Mountains, Antarctica. Geomorphology 12, 323-339.

[6] Hall, K., Thorn, C. E., Matsuoka, N., and Prick, A. (2002) Weathering in cold regions: some thoughts and perspectives. Prog. in Phys. Geogr. 26(4), 577-603.

[7] Rodriguez-Navarro C. and Doehne E. (1999) Salt weathering: influence of evaporation rate, supersaturation and crystallization pattern. Earth Surf. Process Landforms 24, 191-209.

[8] Scherer G. W. (1999) Crystallization in pores. Cem. Concr. Res. 29, 1347-1358. 
[9] Scherer G. W. (2004) Stress from crystallization of salt. Cem. Concr. Res. 34, 1613-162

[10] Benavente D., García del Cura M. A., García-Guinea J., Sánchez-Moral S. and Ordóñez S. (2004) Role of pore structure in salt crystallization in unsaturated stone. J. Cryst. Growth 260, 532-544.

[11] Steiger M. (2005a) Crystal growth in porous materials-I: The crystallization pressure of large crystals. J. Cryst. Growth 282, 455-469.

[12] Shahidzadeh-Bonn N., Desarnaud J., Bertrand F., Chateau X., and Bonn D. (2010) Damage in porous media due to salt crystallization. Phys. Rev. E 81, art. 066110.

[13] Taber S. (1916) The growth of crystals under external pressure. Am. J. Sci. 41A, 532-557.

[14] Correns C. W. (1949) Growth and dissolution of crystals under linear pressure. Discussions of the Faraday Society 5, 267-271.

[15] Desarnaud J., Bonn D. and Shahidzadeh N. (2016) Measurement of the Pressure induced by salt crystallization in confinement. Sci. Rep. 6, 8, art. 30856.

[17] Flatt R.J. (2002) Salt damage in porous materials: how high supersaturations are generated. J. Cryst. Growth 242 435-454.

[18] de Thury H. (1828) Sur le procédé proposé par M. Brard pour reconnaître immédiatement les pierres qui ne peuvent pas résister à la gelée, et que l'on désigne ordinairement par le nom de pierres gelives ou pierres gelisses. Annal. Chimie Physique 38, 160-192.

[19] Yu S. and Oguchi C.T. (2013) Is sheer thenardite attack impotent compared with cyclic conversion of thenardite-mirabilite mechanism in laboratory simulation tests? Engin. Geol. 152(1), 148-154.

[20] Kwaad F. J. M. (1970) Experiments on the disintegration of granite by salt action. University Amsterdam Fysisch Geografisch en Bodemkundig Laboratorium Publicatie 16, 67-80.

[21] Yu S. and Oguchi C.T. (2010) Role of pore size distribution in salt uptake, damage, and predicting salt susceptibility of eight types of Japanese building stones. Engin. Geol. 115(3), 226-236.

[22] Desarnaud J., Bertrand F. and Shahidzadeh N. (2013) Impact of the kinetics of salt crystallization on stone damage during rewetting/drying and humidity cycling. J. Appl. Mech. 80, 020911, 1-7.

[23] Hillel D. (1998) Environmental Soil Physics. Academic Press. 
[24] Toner J.D. and Catling D.C. (2017) A Low-Temperature Thermodynamic Model for the Na-K-Ca-Mg-Cl System Incorporating New Experimental Heat Capacities in $\mathrm{KCl}, \mathrm{MgCl} 2$, and $\mathrm{CaCl} 2$ Solutions. J. Chem. Eng. Data 62 (3), 995-1010.

[25] Steiger M. and Asmussen S. (2008) Crystallization of sulfate phases in porous materials: The phase diagram $\mathrm{Na}_{2} \mathrm{SO}_{4}-\mathrm{H}_{2} \mathrm{O}$ and the generation of stress. Geochim. Cosmochim. Acta 72, 4291-4306.

[26] Desarnaud J., Derluyn H., Carmeliet J., Bonn D. and Shahidzadeh N. (2014) Metastability limit for the nucleation of $\mathrm{NaCl}$ crystals in confinement. J. Phys. Chem. Lett. 5, 890-895.

[27] Derluyn H., Dewanckele J., Boone M.N., Cnudde V., Derome D., and Carmeliet J. (2014) Crystallization of hydrated and anhydrous salts in porous limestone resolved by synchrotron X-ray microtomography. Nucl. Instrum. Methods Phys. Res. B 324, 102-112.

[28] Derluyn H., Saidov T.A., Espinosa-Marzal R.M., Pel L., and Scherer G.W. (2011) Sodium sulfate heptahydrate I: the growth of single crystals. J. Cryst. Growth 329, $44-51$.

[29] Shahidzadeh N. and Desarnaud J. (2012) Damage in porous media: role of the kinetics of salt (re)crystallization. Eur. Phys. J. Appl. Phys. 60, 24205.

[30] Hulin C., Mercury L. (2019a) Capillarity-driven supersolubility in dual-porosity systems. Geochim. Cosmochim. Acta 252, 144-158. https://doi.org/10.1016/j.gca.2019.02.026.

[31] Hulin C., Mercury L. (2019b) Regeneration of capillary water in unsaturated zones. Geochim. Cosmochim. Acta 265, 279-291. https://doi.org/10.1016/j.gca.2019.07.058.

[32] Bouzid M., Mercury L., Lassin A. and Matray J.-M. (2011a) Salt precipitation and trapped liquid cavitation in micrometric capillary tubes. J. Colloid Interface Sci. 360, 768-776.

[33] Bouzid M., Mercury M., Lassin A., Matray J.-M. and Azaroual M. (2011b) In-pore tensile stress by drying-induced capillary bridges inside porous materials. J. Colloid Interface Sci. 335, 494-502.

[34] Tas N.R., Mela P., Kramer T., Berenschot J.W. and van den Berg A. (2003) Capillarity induced negative pressure of water plug in nanochannels. Nano lett. $\mathbf{3}$, 1537-1540.

[35] Tas N.R., Escalante M., van Honschoten J.W., Jansen H.V., and Elwenspoek M. (2010) Capillary Negative Pressure Measured by Nanochannel Collapse. Langmuir 26(3), 1473-1476.

[36] Putnis A. and Mauthe G. (2001) The effect of pore size on cementation in porous rocks. Geofluids 1, 37-41. 
[37] Rijniers L.A., Huinink H.P., Pel L., and Kopinga K. (2005) Experimental evidence of crystallization pressure inside porous media. Phys. Rev. Lett. 94, 075503.

[38] Steiger M. (2005b) Crystal growth in porous materials-II: Influence of crystal size on the crystallization pressure. J. Cryst. Growth 282, 470-481.

[39] Emmanuel S. and Berkowitz B. (2007) Effects of pore-size controlled solubility on reactive transport in heterogeneous rock. Geophys. Research Letters 34, L06404, doi:10.1029/2006GL028962, 5 pages.

[40] Pitzer K.S. (1973) Thermodynamics of electrolytes. I. Theoretical basis and general equations. J. Phys. Chem. 77, 268-277.

[41] Pitzer K.S. (1991) Activity coefficients in electrolyte solutions. CRC Press.

[42] Pitzer K.S. and Mayorga G. (1973) Thermodynamics of electrolytes. II. Activity and osmotic coefficients for strong electrolytes with one or both ions univalent. J. Phys. Chem. 77, 2300-2308. https://doi.org/10.1021/j100638a009

[43] Lassin, A., Azaroual, M., Mercury, L. (2005) Geochemistry of unsaturated soil systems: Aqueous speciation and solubility of minerals and gases in capillary solutions. Geochim. Cosmochim. Acta 69. https://doi.org/10.1016/j.gca.2005.05.020

[44] Toner J.D., Catling D.C., Sletten R.S. (2017) The geochemistry of Don Juan Pond: Evidence for a deep groundwater flow system in Wright Valley, Antarctica. Earth Planet. Sci. Lett. 474, 190-197. https://doi.org/10.1016/j.epsl.2017.06.039

[45] Marion G.M., Farren R.E. (1999) Mineral solubilities in the Na-K-Mg-Ca-Cl-SO4H2O system: A re-evaluation of the sulfate chemistry in the Spencer-Moller-Weare model. Geochim. Cosmochim. Acta 63, 1305-1318. https://doi.org/10.1016/S0016-7037(99)00102-7

[46] Spencer R.J., Møller N., Weare J.H. (1990) The prediction of mineral solubilities in natural waters: A chemical equilibrium model for the $\mathrm{Na}-\mathrm{K}-\mathrm{Ca}-\mathrm{Mg}-\mathrm{Cl}-\mathrm{SO} 4-\mathrm{H} 2 \mathrm{O}$ system at temperatures below $25^{\circ} \mathrm{C}$. Geochim. Cosmochim. Acta 54, 575-590.

[47] Parkhurst D.L. and Appelo C.A.J. (2013) Description of input and examples for PHREEQC version 3: a computer program for speciation, batch-reaction, onedimensional transport, and inverse geochemical calculations, U.S. Geological Survey, Techniques and Methods. Reston, VA. 


\section{Graphical abstract}
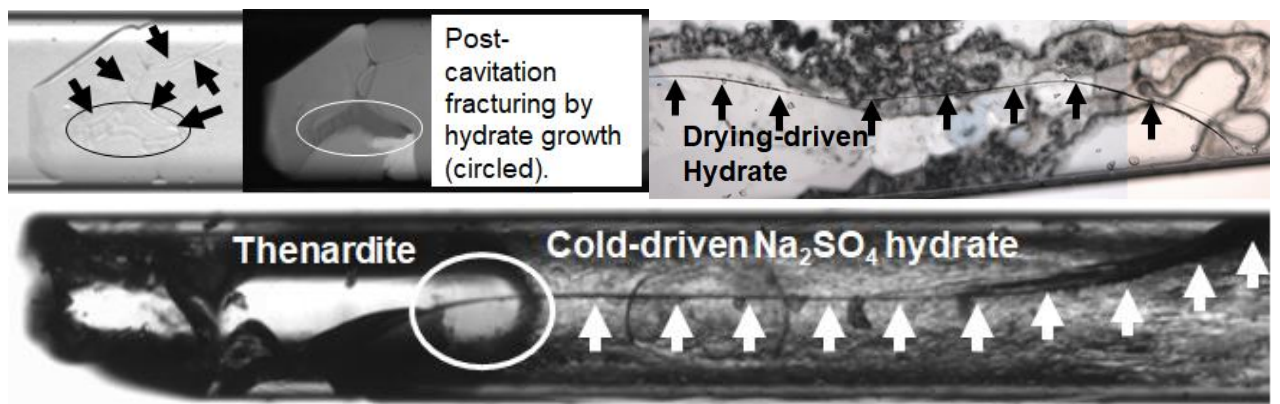

\section{CRediT author statement}

Lionel Mercury, Claudie Hulin: Conceptualization, Methodology, Writing-Original draft preparation.

Lionel Mercury: Supervision, Visualization, Reviewing and Editing.

Claudie Hulin: Investigation.

Arnault Lassin: Formal analysis, Reviewing and Editing.

\section{Declaration of interests}

$\bigotimes$ The authors declare that they have no known competing financial interests or personal relationships that could have appeared to influence the work reported in this paper.

$\square$ The authors declare the following financial interests/personal relationships which may be considered as potential competing interests: 